Article

\title{
Contact Effect of a Methylobacterium sp. Extract on Biofilm of a Mycobacterium chimaera Strain Isolated from a 3T Heater-Cooler System
}

\author{
Inés Pradal ${ }^{1}{ }^{\oplus}$, Jaime Esteban ${ }^{1, *}$, Arancha Mediero ${ }^{2}{ }^{\circledR}$, Marta García-Coca ${ }^{3}$ \\ and John Jairo Aguilera-Correa ${ }^{1}$ (D) \\ 1 Clinical Microbiology Department, IIS-Fundación Jiménez Díaz, UAM, 28040 Madrid, Spain; \\ inespradalap@gmail.com (I.P.); john_j2a@hotmail.com (J.J.A.-C.) \\ 2 Bone and Joint Unit, IIS-Fundación Jiménez Díaz, UAM, 28040 Madrid, Spain; \\ aranzazu.mediero@quironsalud.es \\ 3 Clinical Microbiology Department, Quironsalud-Madrid University Hospital, \\ 28223 Pozuelo de Alarcón, Spain; marta.gcoca@quironsalud.es \\ * Correspondence: jesteban@fjd.es or jestebanmoreno@gmail.com; Tel.: +34-91-550-4900
}

Received: 22 June 2020; Accepted: 29 July 2020; Published: 3 August 2020

\begin{abstract}
Mycobacterium chimaera is an opportunistic slowly growing non-tuberculous mycobacteriumof increasing importance due to the outbreak of cases associated with contaminated 3T heater-cooler device (HCD) extracorporeal membrane oxygenator (ECMO). The aim of this study was to evaluate the effect of pre-treating a surface with a Methylobacterium sp. CECT 7180 extract to inhibit the M. chimaera ECMO biofilm as well as of the treatment after different dehydration times. Surface adherence, biofilm formation and treatment effect were evaluated by estimating colony-forming units ( $\mathrm{CFU}$ ) per square centimeter and characterizing the amount of covered surface area, thickness, cell viability, and presence of intrinsic autofluorescence at different times using confocal laser scanning microscopy and image analysis. We found that exposing a surface to the Methylobacterium sp. CECT 7180 extract inhibited M. chimaera ECMO biofilm development. This effect could be result of the effect of Methylobacterium proteins, such as DNaK, trigger factor, and xanthine oxidase. In conclusion, exposing a surface to the Methylobacterium sp. extract inhibits M. chimaera ECMO biofilm development. Furthermore, this extract could be used as a pre-treatment prior to disinfection protocols for equipment contaminated with mycobacteria after dehydration for at least $96 \mathrm{~h}$.
\end{abstract}

Keywords: Mycobacterium chimaera; 3T HCD; biofilm; Methylobacterium; antibiofilm effect

\section{Introduction}

Mycobacterium chimaera is a strictly aerobic, pleomorphic, non-motile and non-spore forming [1], slowly growing non-tuberculous mycobacterium mainly acting as an opportunistic pathogen [2-4]. $M$. chimaera has been found in several environments such as soil, plants, animals, and especially in water distribution systems. Contagion takes place via natural reservoirs, but never from human to human. Most documented cases of M. chimaera have taken place in Europe and Unites States, where its prevalence is increasing, mostly among immunocompromised patients and individuals with indwelling prosthetic devices [4-6].

The increasing importance of this mycobacterium stems from the numerous cases of disseminated infection associated with the use of 3T HCD extracorporeal oxygenator (LivaNova) [7], an essential medical device employed in open-chest surgeries and one of the best sellers in the world, with $80 \%$ of the devices in commerce [8]. Since 2011, when the first case appeared in Munich (Germany), 
many similar cases have been reported around the world: in Europe (30 cases in United Kingdom, nine in Italy, five in Germany, four in The Netherlands and Ireland, three in France, andone in Spain), in America (18 in United States and, two in Canada), in Asia (at least one case in China), and in Oceania (15 cases in Australia and New Zeeland) [9-19]. Indeed, taking into account that not all the hospital cases are reported in scientific articles, the actual prevalence of $M$. chimaera infections related to the use of 3T HCD extracorporeal could range between 156 and 282 cases in Europe alone [20]. Each case showed a similar past history and symptoms: all patients underwent open-chest surgery, and the main manifestation was prosthetic valve endocarditis [21,22]. Moreover, other clinic manifestations have been described associated to this infection, such as osteoarthritis, spondylodiscitis, breastbone infections, hepatitis, nephritis, and bacteremia [23]. However, there can be between five and 38 months after the cardiac surgery before one can detect any of these symptoms [9]. Noteworthy, M. chimaera is characterized by showing resistance to a great number of antimycobacterial antibiotic and by requiring a treatment from three to six months and at least six months more after a negative sputum culture $[3,24]$. For that, the prognosis associated with these infections is usually poor and has reached a mortality rate of $50 \%$ in United States [6].

All isolated strains from these above-mentioned cases were genetically related and were found in the oxygenation membrane, indicating that this outbreak was an origin contamination, meaning it originated in the factory $[25,26]$. In-depth studies have shown that the infection focus was M. chimaera biofilms on the membrane of the 3T HCD extracorporeal oxygenators, a membrane placed between two water tanks used to maintain blood and cardioplegia solution at a constant temperature and control oxygen level in patient blood [21,22]. Thereupon, $M$. chimaera would reach the bloodstream due to the formation and dispersion of aerosols harboring small pieces of $M$. chimaera biofilm from the membrane [21,22]. Following these reports, the manufacturer of the device recalled a part of the instruments and recommended to use a stricter and deeper disinfection [27] and new revised protocols of use [13,27-29] which turned out to be completely ineffective [30]. Indeed, Food and Drug Administration (FDA) and American and European Control Disease Centers have issued alerts about these disinfections and keep on still monitoring the appearance of new cases $[10,31]$. Thus, to establish new decontamination and treatment strategies in the future, antibiofilm compounds against mycobacteria need to be studied in depth.

A new mycobacterial antibiofilm strategy based on the use of Methylobacterium spp. is currently being developed [32,33]. Methylobacterium is a genus from Alphaproteobacteria isolated by Patt et al. [34] that is a strictly aerobic bacterium and forms small rose colonies at its optimal growth temperature $\left(25^{\circ} \mathrm{C}\right)$ and usually inhabits water distribution systems [32,35]. Some strains of Methylobacterium genus have already demonstrated antibacterial effect against different microorganisms, both Gram-positive and Gram-negative bacteria [36-38], including mycobacteria [33], and fungi [36].

Therefore, the aim of this study was to evaluate the contact effect of a Methylobacterium sp. extract to inhibit and treat the biofilm of a M. chimaera strain isolated from a 3T HCD extracorporeal oxygenator membrane.

\section{Results}

\subsection{Methylobacterium sp. CECT 7180 Does Not Inhibit M. chimaera ECMO Adherence}

Non-significant differences were detected between M. chimaera ECMO adherence to the control surface and to a surface treated with the Methylobacterium s $p$. CECT 7180 extract ( $p$-value $=0.8336$ for Wilcoxon test) (Figure 1), indicating that the Methylobacterium sp. CECT 7180 extract has no anti-adherent effect on M. chimaera ECMO. 


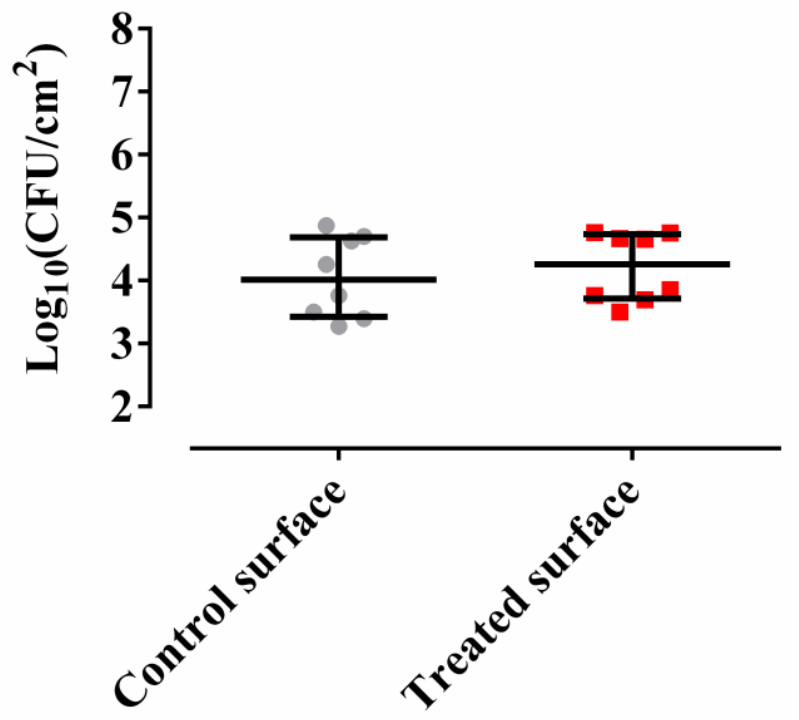

Figure 1. M. chimaera ECMO adherence to a control surface (gray) and a surface treated with Methylobacterium sp. CECT 7180 extract (red). The bars represent the interquartile range.

\subsection{Methylobacterium sp. CECT 7180 Inhibits the Formation of M. chimaera ECMO Biofilm}

The treatment of a surface with the Methylobacterium sp. CECT 7180 extract decreased biofilm formation. This could be observed macroscopically, and by comparing colony forming units per area count on a control surface, $\log _{10}\left(\mathrm{CFU} / \mathrm{cm}^{2}\right)=6.836$, with those on a treated surface, $\log _{10}\left(\mathrm{CFU} / \mathrm{cm}^{2}\right)=4.357$ ( $p$-value $=0.0008$ for Wilcoxon test) (Figure 2). It is noteworthy to highlight that the adhered colony forming units per area count on a treated surface did not change with the time, and there were no significative differences between the number of adhered bacteria on a treated surface after the $90 \mathrm{~min}$ of exposure $\left(\log _{10}\left(\mathrm{CFU} / \mathrm{cm}^{2}\right)=4.26\right)$ and the number of adhered bacteria on a treated surface and grown in Middlebrook for $120 \mathrm{~h}\left(\log _{10}\left(\mathrm{CFU} / \mathrm{cm}^{2}\right)=4.357\right)$ in the same surface $(p$-value $=0.8541$ for Wilcoxon test).

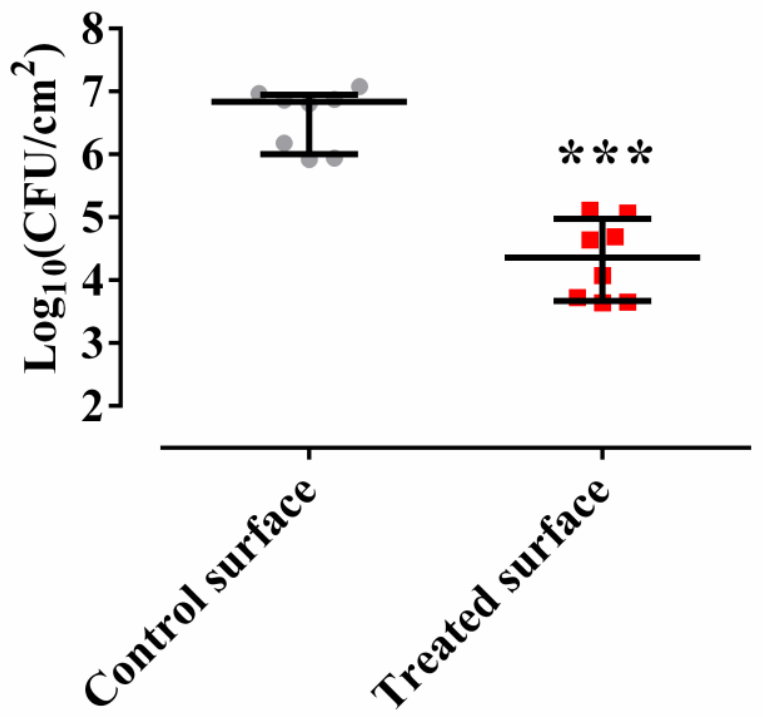

Figure 2. M. chimaera ECMO biofilm formation on a control surface (gray) or on a surface treated with Methylobacterium sp. CECT 7180 extract (red). The bars represent the interquartile range. *** $p$-value $<0.001$ for Wilcoxon test. 
The process of M. chimaera ECMO biofilm growth was characterized over $120 \mathrm{~h}$ by confocal laser microscopy on a control surface and on a surface that had been treated with Methylobacterium sp. CECT 7180 extract. The biofilm formation process on the control surface showed a slight reduction over time of the viable bacteria, since significant differences were found between 24 and $48 \mathrm{~h}$ ( $p$-value $<0.0001$ for Wilcoxon test), 48 and $72 \mathrm{~h}$ ( $p$-value $=0.0057$ for Wilcoxon test), and 96 and $120 \mathrm{~h}$ ( $p$-value $=0.0101$ for Wilcoxon test) (Figure 3A, in black). The biofilm grew in thickness over time ( $p$-value $<0.0001$ for Kruskal-Wallis test) (Figure 3B, in black) but did not change the covered surface ( $p$-value $=0.3669$ for Krustal-Wallis test) (Figure 3C, in black). Relative autofluorescence was similar between 24 and $48 \mathrm{~h}$ ( $p$-value $=0.6789$ for Wilcoxon test) and significantly increased from 72 to $120 \mathrm{~h}$ ( $p$-value $<0.0001$ for Wilcoxon test) (Figure 3D, in black).

A.
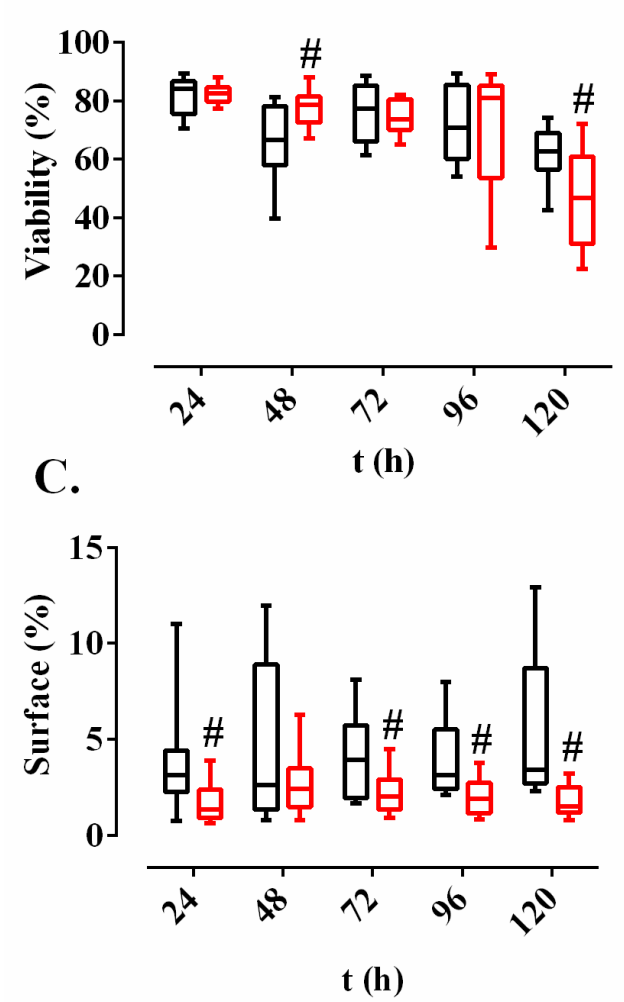

B.
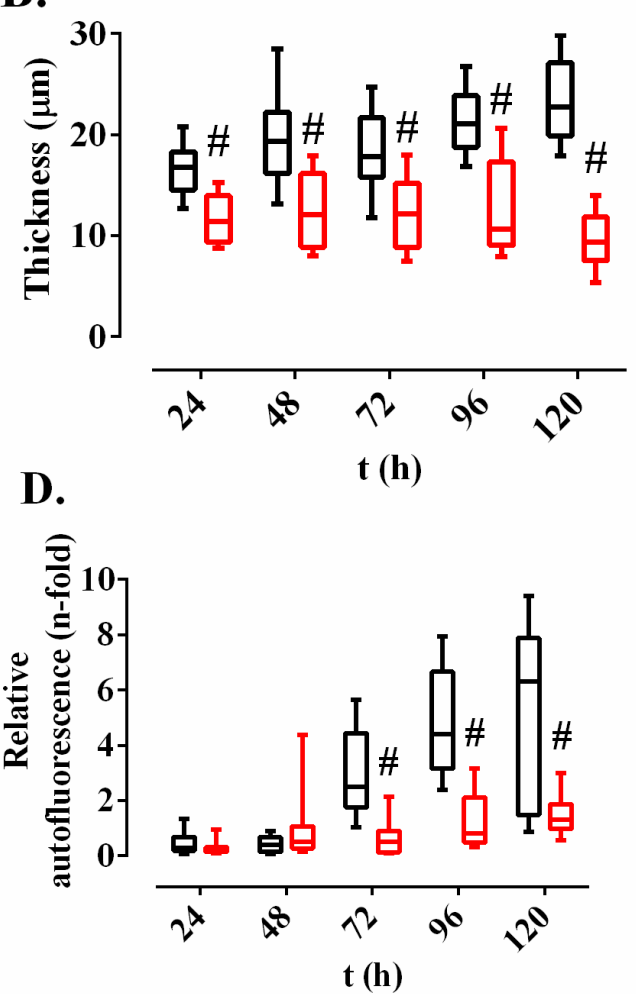

Figure 3. M. chimaera ECMO biofilm development over time on a control surface (black) and on a surface treated with Methylobacterium extract (red). The four parameters evaluated were (A) mycobacterial viability (\%); (B) biofilm thickness ( $\mu \mathrm{m})$; (C) biofilm covered surface $(\%)$; and (D) relative autofluorescence (n-fold). The boxes represent the median and interquartile range and the bars indicate tenth and ninetieth percentiles. \#: $p$-value $<0.001$ for Wilcoxon test between on a control surface and on a surface treated with Methylobacterium sp. CECT 7180 extract.

The biofilm grown on the surface treated with Methylobacterium extract showed a slight but statistically significant reduction between 24 and $48 \mathrm{~h}$ ( $p$-value $=0.0026$ for Wilcoxon test), and a substantial decrease of the viable bacteria (\%) between 96 and $120 \mathrm{~h}$ ( $p$-value $=0.0001$ for Wilcoxon test) (Figure 3A, in red). Thickness showed non-significant differences between 24 and $96 \mathrm{~h}$ ( $p$-value $=0.9611$ for Kruskal-Wallis test), but at $120 \mathrm{~h}$ it significantly decreased ( $p$-value $=0.0223$ for Wilcoxon) (Figure 3B, in red). However, covered surface increased between 24 and $48 \mathrm{~h}$ ( $p$-value $=0.0163$ for Wilcoxon test) and, from this time, there were no significant differences over time (Kruskal-Wallis $p$-value $=0.9611$ ) (Figure 3C, in red). Finally, relative autofluorescence increased slightly but significantly between 24 and $48 \mathrm{~h}$ ( $p$-value $=0.0004$ for Wilcoxon test) and between 72 and $96 \mathrm{~h}(p$-value $=0.0078$ for Wilcoxon test) but showed no differences for other times (Figure 3D, in red). 
When both surface conditions were compared, the following differences were detected (Figure 3): thickness, surface covered, and relative autofluorescence were significantly lower in the biofilm grown on the surface treated with Methylobacterium extract. These differences can be also seen in the 3D reconstructions (Figure 4).
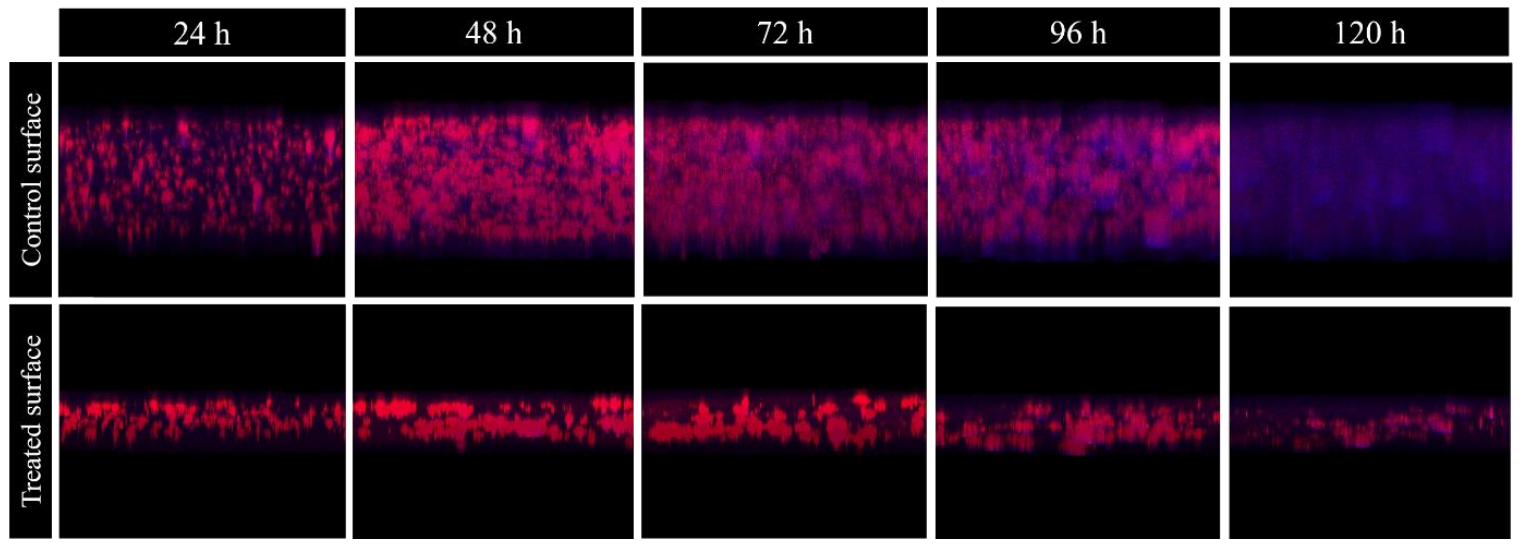

Figure 4. 3D structure of $M$. chimaera ECMO biofilms of different ages $(24,48,72,96$, and $120 \mathrm{~h})$, grown on a control surface (control) or on a treated surface with Methylobacterium sp. CECT 7180 (Treated). In red, the red Nile stain which corresponds to the wall of mycobacteria forming the biofilm, and in blue, the relative autofluorescence, which would correspond to the biofilm matrix.

\subsection{Effect of Methylobacterium sp. CECT 7180 Extract on M. chimaera ECMO Biofilms Dehydrated for} Different Time Periods

Dehydration from 24 to $96 \mathrm{~h}$ did not decrease the mycobacterial viability over time $(p$-value $=0.1239$ for Kruskal-Wallis), but there was a significant decrease between 96 and $120 \mathrm{~h}$ ( $p$-value $=0.0008$ for Wilcoxon test) (Figure 5).

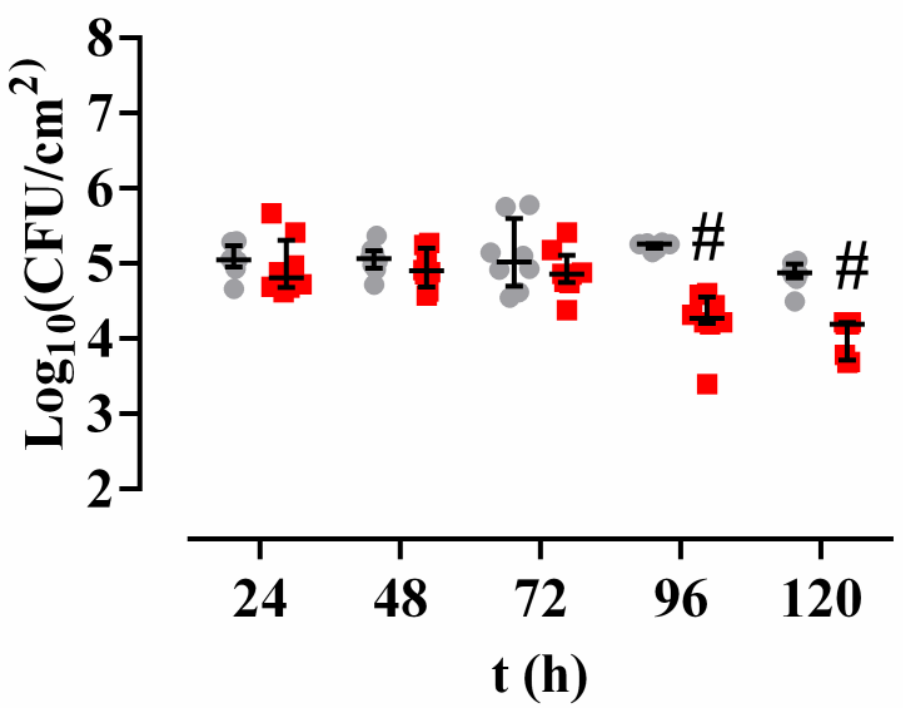

Figure 5. Amount of M. chimaera ECMO per area unit after different times of dehydration and treated (red) or not (gray) with Methylobacterium extract. The bars represent the interquartile range. $\#: p$-value $<0.001$ for Wilcoxon test between a control treatment or a treatment with Methylobacterium sp. CECT 7180 extract.

Treatment with Methylobacterium extract did not have any effect on biofilms dehydrated for 24, 48, or $72 \mathrm{~h}$ (Figure 5) ( $p$-value $=0.5588$ for Kruskal-Wallis test). However, treatment with the Methylobacterium extract provoked a significant drop in the viability of the biofilms dehydrated for 96 
and for $120 \mathrm{~h}$ (Figure 5), therefore it can be said that the treatment with Methylobacterium extract was only effective after 96 and/or $120 \mathrm{~h}$ of desiccation at room temperature $(p$-value $<0.001)$.

\subsection{Study of Adhered Proteins of Methylobacterium sp. CECT 7180 Extract}

With silver staining, at least three prominent single groups of bands were observed (Figure 6A). The three groups of bands were cut out in the gel from the detached proteins from Methylobacterium spp. extract adhesion washed twice, since it had less background (Figure 6B).

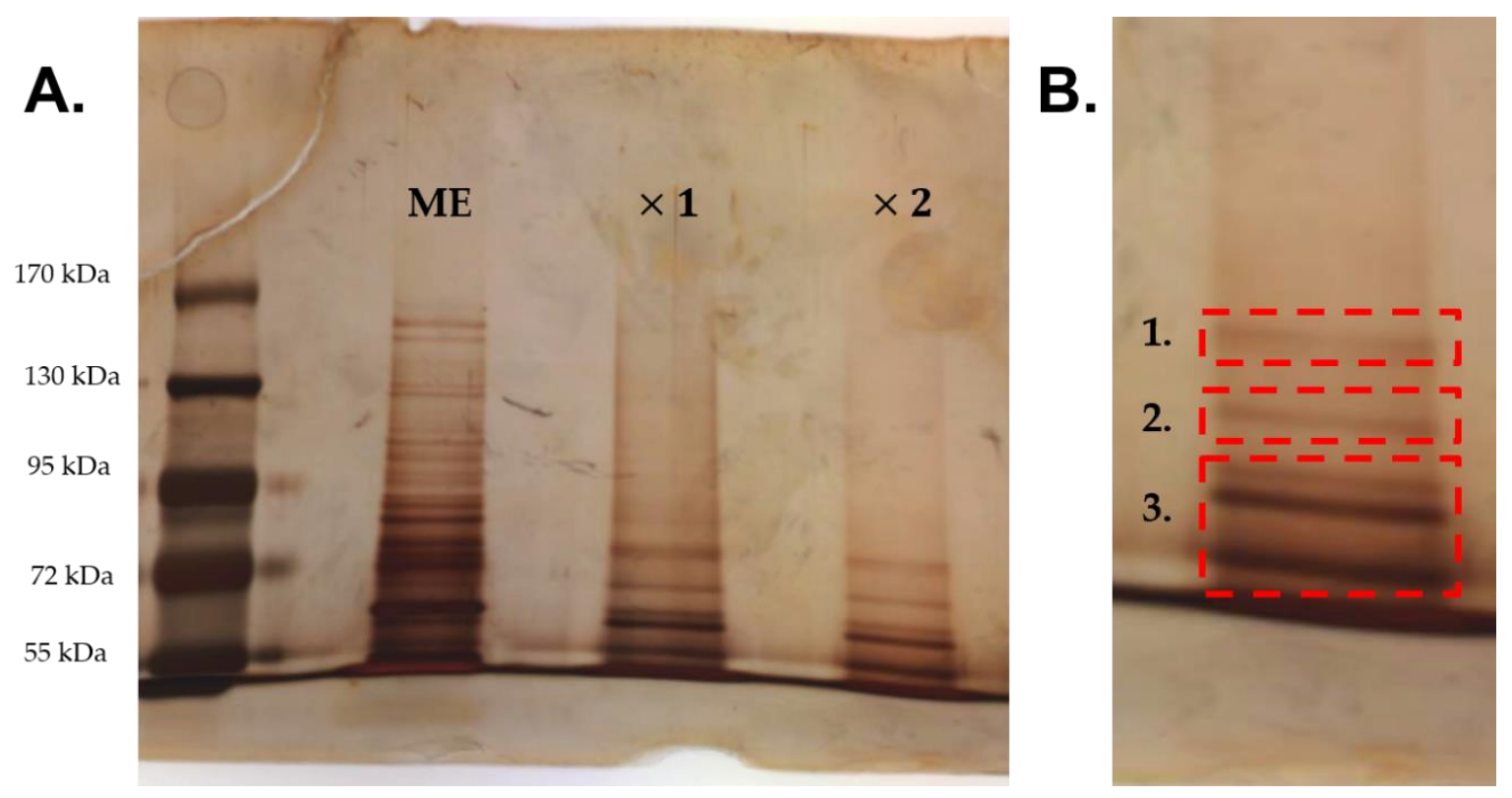

Figure 6. Silver stained protein band pattern of pure Methylobacterium sp. extract (ME) and detached proteins from Methylobacterium $s p$. extract adhesion washed once $(\times 1)$ or twice $(\times 2)$ separated by SDS Polyacrylamide Gel Electrophoresis (PAGE) (A); Bands selected for LC-MS/MS analysis (B).

A total of 21 proteins were identified by Liquid Chromatography Electrospray Ionization Tandem Mass Spectrometric (LC ESI-MS/MS) in the bands cut out and are included in the Table 1. Six Methylobacterium sp. proteins showed more than one peptide and were considered predominant in each band (Table 1, in bold). In band 1, an elongation factor $\mathrm{G}$ was identified among other proteins. In band 2, a translation initiation factor 2, a molecular chaperone DnaK, a 30S ribosomal protein S1 and a xanthine oxidase family protein molybdopterin-binding subunit were identified among other proteins. In band 3, a trigger factor was mainly identified among other proteins.

Table 1. Proteins identified in each gel band by Liquid Chromatography Electrospray Ionization Tandem Mass Spectrometric (LC ESI-MS/MS).

\begin{tabular}{|c|c|c|c|c|c|}
\hline Band & UniProt ID & Peptide Sequences & Protein Name & Species & Score $^{\mathrm{a}}(p<0.05)$ \\
\hline \multirow{5}{*}{1} & A0A512JN39 & $\begin{array}{l}\text { K.LAAEDPSFR.V } \\
\text { K.LAAEDPSFR.V } \\
\text { K.LAAEDPSFR.V }\end{array}$ & Elongation factor $\mathrm{G}$ & $\begin{array}{l}\text { Methylobacterium } \\
\text { gnaphalii }\end{array}$ & 82 \\
\hline & A0A2R4WM33 & R.GSRATVSLPR.A & $\begin{array}{l}\text { Glutathione-dependent } \\
\text { formaldehyde dehydrogenase }\end{array}$ & $\begin{array}{l}\text { Methylobacterium } \\
\text { currus }\end{array}$ & 50 \\
\hline & A0A5A8ABH1 & R.AEFAESAR.A & Uncharacterized protein & $\begin{array}{l}\text { Methylobacterium } \\
\text { sp. P1-11 }\end{array}$ & 37 \\
\hline & A0A0X1SN19 & K.TLEDLR.D & Glycerol kinase & $\begin{array}{l}\text { Methylobacterium } \\
\text { sp. DM1 }\end{array}$ & 37 \\
\hline & A0A2R4WQJ0 & R.VALANQR.Q & SLBB domain-containing protein & $\begin{array}{l}\text { Methylobacterium } \\
\text { currus }\end{array}$ & 31 \\
\hline
\end{tabular}


Table 1. Cont.

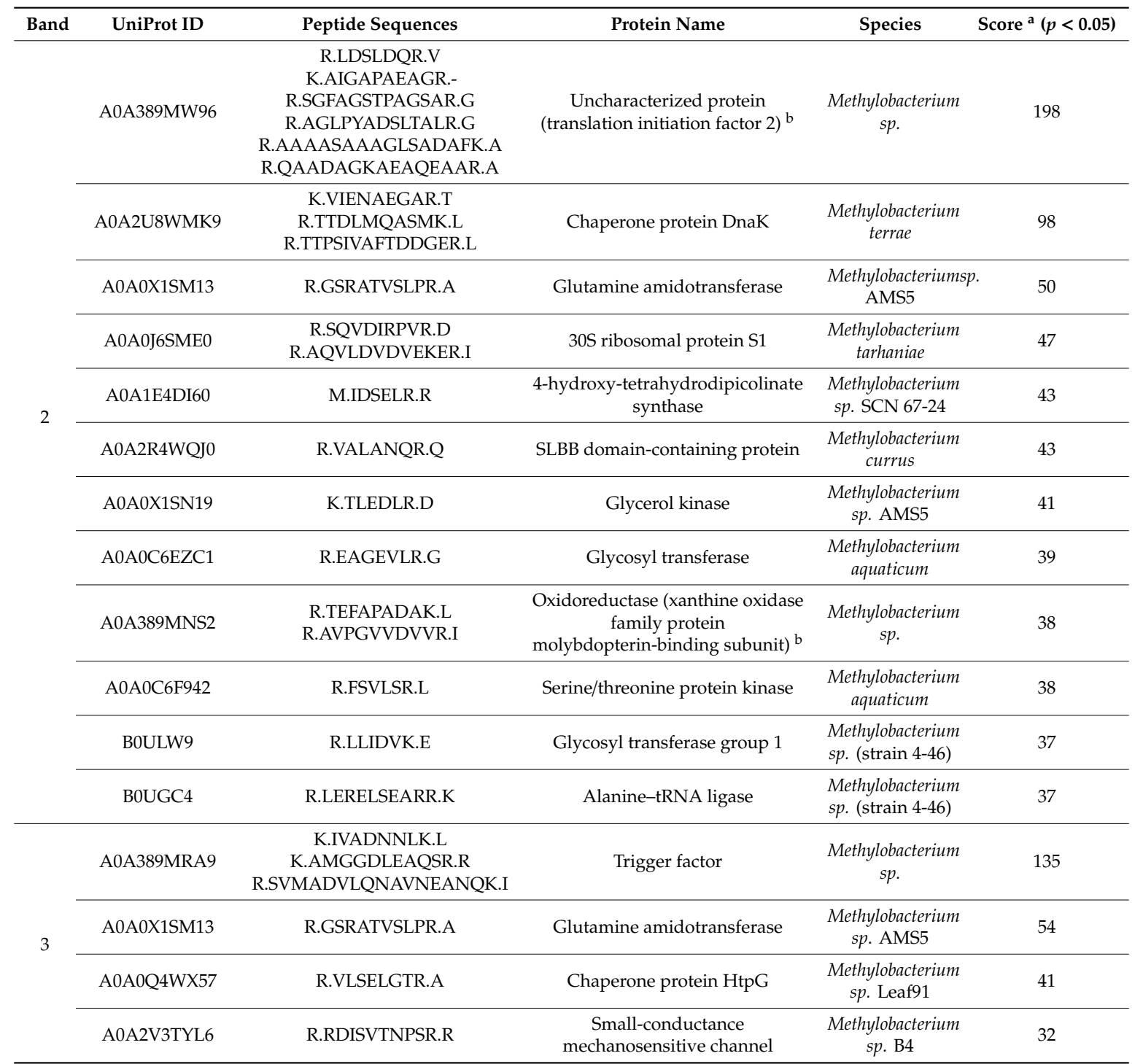

${ }^{\mathrm{a}}$ Ion score is $-10^{*} \log (\mathrm{P})$, where $\mathrm{P}$ is the probability that the observed match is a random event. Individual ion scores $>16$ indicated identity or extensive homology $(p$-value $<0.05)$. Proteins with two or more peptides were considered majoritarian in each band and are in bold. ${ }^{b}$ Protein identification by Basic Local Alignment Search Tool (BLAST) according to UniProt sequence.

\section{Discussion}

This study demonstrates that the Methylobacterium sp. extract can inhibit the M. chimaera ECMO biofilm development when it is used to treat a plastic surface. Further, we demonstrated a possible alternative method to decontaminate 3T HCD extracorporeal oxygenator membranes after allowing the oxygenators to dry at room temperature for at least four or five days.

As in many microorganisms, mycobacterial biofilm development starts with an adherence stage, and then proceeds to the maturation stage, which consists of sessile growth and matrix synthesis and, finally, the dispersion [32]. The M. chimaera ECMO biofilm formation process is highly similar to the constant mycobacterial viability of $M$. mageritense [39]. Interestingly, there was a slightly but statistically significant reduction of the viability in the control condition that might be due to a controlled autolysis which may justify the modest increase of the relative autofluorescence at $72 \mathrm{~h}$ to favor the biofilm development [40]. The M. chimaera ECMO biofilm formation process is also similar to the absence of surface growth over time of $M$. mageritense, the vertical growth of Mycobacterium peregrinum, and the autofluorescence increase from 24 to $48 \mathrm{~h}$ of $M$. chelonae, M. peregrinum, and M. fortuitum [39]. 
In our study, the effect of the Methylobacterium extract did not compromise M. chimaera adherence. By contrast, other Methylobacterium strains have been found to exert an anti-adherent effect on Mycobacterium avium [35]. According to our results, the action of the Methylobacterium extract adhered on a surface takes place after the mycobacterial adherence.

The thickness, surface coverage, and relative autofluorescence of the $M$. chimaera ECMO biofilm were significantly lower on surfaces treated with Methylobacterium extract. The most critical effect of the Methylobacterium extract was the significant inhibition of relative autofluorescence. Relative autofluorescence is mainly caused by F420 coenzyme presence in the mycobacterial wall and biofilm matrix [32]. Therefore, a decrease in relative autofluorescence, when the bacterial viability remains relatively constant over time, indicates a decrease in biofilm matrix synthesis. As biofilm formation is regulated by quorum-sensing [41], we hypothesize that this Methylobacterium extract may also exert a quorum quenching-like effect on $M$. chimaera ECMO. This antibiofilm effect has also been described in other rapidly growing non-tuberculous mycobacteria, such as Mycobacterium abscessus, Mycobacterium fortuitum, and Mycobacterium chelonae [35]. This antibacterial effect has been described in other Methylobacterium strains, for instance, the ERI-135 strain isolated from the soil whose ethyl acetate extract inhibited the growth of bacteria such as Bacillus subtilis, Klebsiella pneumoniae, Pseudomonas aeruginosa, Salmonella typhimurium, Shigella flexneri, Enterobacter aerogenes, Staphylococcus aureus and S. epidermidis and fungi, such as Candida albicans and Trichophyton rubrum [38]; the Methylobacterium radiotolerans MAMP 4754 isolated from the seeds of the river bushwillow (Combretum erythrophyllum (Burch.) Sond), whose ethyl acetate and chloroform extracts also showed antibacterial effect on B. subtilis, B. cereus, Escherichia coli, K. oxytoca, and Mycobacterium smegmatis [40]; and Methylobacterium extorquens DSM13060, an intracellular meristem endophyte of scots pine (Pinus sylvestris L.), whose defensin-like antimicrobial peptide MB1533 showed an inhibitory effect on S. aureus and B. subtilis [37]. Moreover, a similar effect has already been described for other bacterial extracts, such as Delftia tsuruhantensus extract, which showed antibiofilm activity against $P$. aeruginosa [42], or even some mycobacteria, such as $M$. avium, which can produce lactonase and degrade quorum-sensing autoinducers of Proteobacteria [43].

This anti-mycobacterial effect may be due to at least three non-exclusive causes: (1) the effect of $\mathrm{DNaK}$ and trigger factor, (2) the reactive oxygen species (ROS) generated by the xanthine oxidase and (3) the "hijacking" of pyridoxine by the xanthine oxidase. All remaining majority proteins (translation initiation factor 2, a 30 S ribosomal protein S1, and the elongation factor $\mathrm{G}$ ) and minority proteins were not considered because they used to be intimately linked with the ribosomal complex [44-46] or cytoplasmatic proteins, respectively. Firstly, we hypothesize that DNaK and trigger factor may link to M. chimaera ECMO surface and block some proteinic receptors related with intercellular communication, since the clients of these two chaperones are enriched proteins with low intrinsic solubility, proteins that tend to be members of hetero-oligomeric complexes and/or proteins that show a high density of hydrophobic patches flanked by positive [47], similar to those proteins which may be found in the non-tuberculous mycobacteria walls that at the same time are surrounded by a lipid-rich outer membrane that make them intrinsically hydrophobic and impermeable [48]. This would back up our hypothesis of the quorum quenching-like effect which Methylobacterium extract might exert on $M$. chimaera ECMO. Secondly, xanthine oxidase molybdopterin binding subunit might be surely result of conversion from the xanthine dehydrogenase molybdopterin binding subunit form, a very common type of enzyme found in Methylobacterium genus [49], to the oxidase form irreversibly by proteolysis or reversibly through oxidation of sulphydryl groups [50]. Most of these kinds of xanthine oxidases have the capability of reducing molecular oxygen and producing superoxide radical anion and hydrogen peroxide at proportions that depend on the substrate and oxidation conditions [51]. In our experimental conditions, the presence of gaseous carbon dioxide would favor the bicarbonate generation [52], and this bicarbonate would favor the superoxide radical anion [51]. This ROS may have an inhibitory effect on the M. chimaera ECMO due to its susceptibility to them [53]. Thirdly, it has been reported that the pyridoxine present in the growth broth used inhibits the action of certain 
xanthine oxidases, e.g., human xanthine oxidase [54]. This "hijacking" by the xanthine oxidase would reduce the concentration of pyridoxine, which in turn would reduce the mycobacterial growth rate because it is necessary for the correct growth of certain mycobacteria [55].

After the alarm provoked by the increasing number of $M$. chimaera infection cases associated with 3T HCD extracorporeal oxygenator, the manufacturer modified the indications for equipment disinfection, such as the time intervals of water change in the circuit, the time required between disinfection procedures, and the type of disinfectants to be used [8,29]. However, these changes were insufficient to completely eliminate the M. chimaera biofilm, and new cases of infection continued to appear [8,29]. Here, we demonstrate that a short dehydration period (four or five days) at room temperature followed by a 15-min treatment of Methylobacterium extract can reduce between $79 \%$ and $90 \%$ the $M$. chimaera biofilm adhered to a plastic surface. This treatment could be used before disinfecting contaminated equipment. In this same line of thought, Falkinham et al. [56] have recently proposed the use of a combination of enzymes, detergents and bleach as disinfestation treatment, since its use delays the reappearance of $M$. chimaera. It should be noted that the number of mycobacteria per area decreased between 96 and $120 \mathrm{~h}$ in the control condition, just at the same times when the extract was effective. Though it is known that most mycobacteria resist destruction for long periods in the dry state in the absence of sunlight [57] and that non-homologous end-joining pathway is involved in this phenomenon at least in Mycobacterium smegmatis [58], this does not mean that mycobacterial biofilms do not reduce their bacterial concentration over time at room temperature. This viability reduction may be result of an autolytic mechanism of certain mycobacteria from biofilm which would immolate themselves for the sake of their adjacent congeners [40,59], at the same time that they would weaken structurally their biofilm and make it more permeable $[59,60]$ to the Methylobacterium extract and its antimycobacterial effect. These results might support the use of this extract with antibiotics or antiseptics after desiccation period of the equipment, since the Methylobacterium extract used in combination with clarithromycin was able to inhibit the M. abcessus biofilm development over time by reducing the biofilm covered area and its thickness compared to the clarithromycin control [61].

This work is not exempt from some limitations. Firstly, the results of this study can be only strictly applied to the $M$. chimaera ECMO strain isolated from a 3T HCD extracorporeal oxygenator. Despite of its clinical importance for being directly related to this concrete outbreak, the antibacterial contact effect of the extract should be tested in other M. chimaera strains, a cocktail of strains or even other Mycobacterium species. Moreover, this Methylobacterium extract has demonstrated to have diverse effects in different rapidly growing non-tuberculous mycobacteria [33,62]. Therefore, this study should be taken as exploratory in nature. Secondly, the antimycobacterial effect has been proven in laboratory conditions, in a surface different from the surface where this strain was isolated. For that, further investigations with this extract should be performed on other surfaces, as well as by using other biofilm development methodologies, because the molecules attached on each kind of surface may be different depending on the surface nature. Thirdly, it would be necessary to provide a proof-of-concept associated with the proteins identified separately or in combination. Furthermore, it should be ruled out that proteins smaller than those identified in this study were involved in the antimycobacterial effect of the extract. Fourthly, the use of this Methylobacterium extract would be uniquely limited to inert surface.

\section{Materials and Methods}

\subsection{Bacterial Strains and Culture Conditions}

We used a strain of Mycobacterium chimaera isolated from a 3T HCD extracorporeal oxygenator membrane (LivaNova, London) (M. chimaera ECMO). The strain was kept frozen at $-80{ }^{\circ} \mathrm{C}$ until the experiments were performed.

M. chimaera was grown on Middlebrook 7H10 agar (BD, Franklin Lakes, NJ, USA) culture plates for at least five days. Before each experiment, $0.5 \mathrm{~mL}$ of a $2.00 \pm 0.02 \mathrm{McFarland}$ suspension of $\mathrm{M}$. chimaera 
ECMO made in 0.9\% saline was inoculated in a Bact/Alert MP bottle (Biomérieux, îlle de France, France) supplemented with $0.5 \mathrm{~mL}$ of antibiotic supplement following manufacturer instructions. The suspension was then incubated for at least $120 \mathrm{~h}$ at $37^{\circ} \mathrm{C}$ and $5 \% \mathrm{CO}_{2}$ atmosphere [33].

\subsection{Methylobacterium sp. CECT 7180 Extract Elaboration}

Following the methodology previously described by García-Coca et al. [33], a 4-McFarland suspension of Methylobacterium sp. CECT 7180 from Spanish Type Culture Collection (Colección Española de Cultivos Tipo, CECT) was made in phosphate buffer saline (PBS) (Biomérieux, Îlle de France, France). This suspension was sonicated, using a Ultrasons-FB 15053 low-power bath sonicator (Thermo Fisher Scientific, Millersburg, PA, USA), three times for $30 \mathrm{~s}$ in ice at 100 Amp, leaving $5 \mathrm{~min}$ between each sonication. It was then centrifuged at $5000 \times g$ at $4{ }^{\circ} \mathrm{C}$ for $10 \mathrm{~min}$ (Thermo Scientific ${ }^{\mathrm{TM}}$ Sorvall ${ }^{\mathrm{TM}}$ ST 16 Centrifuge). Finally, the supernatant was stored and kept at $-25^{\circ} \mathrm{C}$ until use.

\subsection{M. chimaera ECMO Adherence Study}

For the study of the adherence of $M$. chimaera ECMO, the protocol previously described by García-Coca et al. [33], with some modifications, was employed as follow. Bact/Alert MP flasks inoculated for $120 \mathrm{~h}$ were centrifuged at $1160 \times \mathrm{g}$ for $10 \mathrm{~min}$ (Thermo Scientific ${ }^{\mathrm{TM}}$ Sorvall ${ }^{\mathrm{TM}}$ ST 16 Centrifuge) and washed three times with PBS. A 0.5 McFarland suspension was made with the pellet in PBS. At the same time, four wells from a six-well plate were treated at room temperature for 15 min: two with $1 \mathrm{~mL}$ of PBS (control) and the other two with $1 \mathrm{~mL}$ of Methylobacterium sp. CECT 7180 extract. After $15 \mathrm{~min}$, the supernatant was removed, and each well was washed once with PBS. Next, $1 \mathrm{~mL}$ of the $0.5 \mathrm{McF}$ arland suspension was added to each well and the plate was incubated at $37^{\circ} \mathrm{C}$ and $5 \% \mathrm{CO}_{2}$ atmosphere for $90 \mathrm{~min}$. The supernatant was removed, and all wells were washed once with PBS. Three $\mathrm{ml}$ of PBS were added to each well and the plate was sonicated using a Ultrasons-FB 15,053 low-power bath sonicator (Thermo Fisher Scientific, Pennsylvania, USA) at room temperature for $5 \mathrm{~min}$. Finally, the bacterial concentration by surface area was quantified using the drop plate method [63] in Middlebrook 7H10 agar plates that were incubated for at least 10 days. This experiment was performed in triplicate.

\subsection{Inhibition of M. chimaera ECMO Biofilm Formation}

For the study of the formation of $M$. chimaera ECMO biofilm, the protocol described by García-Coca et al. [33], with some modifications, was employed as follow. After performing the adherence protocol described above on each condition, the supernatant was removed, and the wells were washed once with PBS before adding $5 \mathrm{~mL}$ of Middlebrook 7H9 broth (BD, New Jersey, USA) in each well. The plate was incubated for $120 \mathrm{~h}$ at $37^{\circ} \mathrm{C}$ and $5 \% \mathrm{CO}_{2}$ atmosphere. After this incubation, the medium was removed, and each well was washed once with PBS. Next, biofilms formed at the bottom of the well were scraped with sterile wood sticks inserted in a 50-mL Falcon tube (Falcon, Corning, Corning, NY, USA) filled with $10 \mathrm{~mL}$ (control surface) or $5 \mathrm{~mL}$ (treated surface) of PBS. The wooden sticks were sonicated for $5 \mathrm{~min}$ at room temperature. The bacterial concentration was quantified by means of the drop plate method [63] in Middlebrook 7H10 agar plates incubated for at least 10 days. This experiment was performed in triplicate.

\subsection{Formation of M. chimaera ECMO Biofilm}

The effect of the Methylobacterium sp. CECT 7180 extract on M. chimaera ECMO biofilm was evaluated at 24, 48, 72, 96, and $120 \mathrm{~h}$ using hydrophobic uncoated sterile slide $2 \times 4$-well plates (Ibidi GmbH, Martinsried, Germany) according to the methodology previously described by García-Coca et al. [33] and Muñoz-Egea et al. [39]. For each time point, one well was treated with $300 \mu \mathrm{L}$ of PBS (control surface), and another well was treated with the same volume of the Methylobacterium extract (treated surface). A M. chimaera ECMO 0.5 McFarland suspension was made and $300 \mu \mathrm{L}$ was inoculated in each well. Inoculated wells were incubated for $30 \mathrm{~min}$ at $37^{\circ} \mathrm{C}$ and $5 \% \mathrm{CO}_{2}$ atmosphere. 
The supernatant was removed, and each well was washed once with PBS. Then, $300 \mu \mathrm{L}$ of Middlebrook $7 \mathrm{H} 9$ broth was added to each well, and the plate was incubated in an orbital shaker $(80 \mathrm{rpm})$ at $37^{\circ} \mathrm{C}$ for each development time. After each time, wells were washed once with $300 \mu \mathrm{L}$ PBS. The wells were then stained using the Live/Dead BacLight ${ }^{\mathrm{TM}}$ Bacterial Viability Kit for microscopy (Thermo Fisher Scientific, PA, USA) and the Nile Red stain (Sigma-Aldrich Co., St. Louis, MO, USA). Stains were performed according to the instructions provided by the manufacturer. After staining, plates were analyzed using a Leica DM IRB confocal laser-scanning microscope (Leica, Wetzlar, Germany): one set of wells was used to study both relative autofluorescence and Nile Red stain (covered surface), and the other was used to analyze the percentage of live mycobacteria. Each situation was studied by taking 10 random microphotographs for each stain and time set, and they were analyzed using ImageJ software (National Institutes of Health, Bethesda, MD, USA). Biofilm thickness was measured at 10 random points per well and relative autofluorescence was measured as the coefficient resulting from dividing the percentage of relative autofluorescence of covered surface by the percentage of Nile Red covered surface. This experiment was performed in triplicate.

\subsection{Desiccation Resistance of M. chimaera ECMO Biofilms}

For the study of the desiccation of M. chimaera ECMO biofilms, a modification of the protocol described by García-Coca et al. [33] was used. The previous protocol used on an untreated surface was performed to create 120-h M. chimaera ECMO biofilms in four wells of a six-well plate. The biofilms formed were left to dry at room temperature for 24, 48, 72, 96, or $120 \mathrm{~h}$. After each time of dehydration, two wells were treated with $1 \mathrm{~mL}$ of PBS and the other two with $1 \mathrm{~mL}$ of Methylobacterium sp. CECT 7180 extract for $15 \mathrm{~min}$; each treatment was performed in duplicate. Then, each well was washed once with PBS, biofilms were scraped with sterile wood sticks, and the previous protocol was applied. This experiment was performed in triplicate.

\subsection{Statistical Analysis}

Statistical analysis was performed using Stata statistical software, Release 11 (StataCrop 2009). We used a non-parametric Wilcoxon test to compare two data sets and a non-parametric Kruskal-Wallis test when more than two data sets were being compared. Statistical significance was set at $p<0.05$. Values are provided as median and interquartile range.

\subsection{Study of Adhered Proteins of Methylobacterium sp. CECT 7180 Extract}

Two wells from a six-well plate (Fisher Scientific, PA, USA) were treated at room temperature for 15 min: two with $1 \mathrm{~mL}$ of PBS (control) and the other two with $1 \mathrm{~mL}$ of Methylobacterium sp. CECT 7180 extract. After $15 \mathrm{~min}$, the supernatant was removed; one of the wells of each condition was washed once whilst the other one was washed twice with PBS.

The adhered proteins on each well were detached by using a modified methodology previously described by Conesa-Buendía et al. [64]. Briefly, $200 \mu \mathrm{L}$ of RIPA buffer containing protease/phosphatase inhibitors (Sigma-Aldrich Co., St. Louis, MO, USA) and LB buffer (Thermo Fisher Scientific, Massachusetts, USA) for denaturalization were added and heated at $105^{\circ} \mathrm{C}$ for $1.5 \mathrm{~min}$. The supernatant with detached proteins was collected and store at $-25^{\circ} \mathrm{C}$ before to be used. Protein concentration was determined using bicinchoninic acid (Thermo Fisher Scientific, Massachusetts, USA). Twenty-five microliters (approximately $3 \mu \mathrm{g}$ of protein per sample) of the detached protein were run in a $6 \%$ SDS-polyacrilamide gel. Silver staining was performed as previously described [56]. Briefly, after fixing in 50\% methanol plus 5\% acetic acid for $20 \mathrm{~min}$ and 50\% methanol for $10 \mathrm{~min}$, the gel was washed with ultrapure water overnight. The gel was sensitized in $0.02 \% \mathrm{Na}_{2} \mathrm{~S}_{2} \mathrm{O}_{3}$ for $1 \mathrm{~min}$ and then stained with $0.1 \% \mathrm{AgNO}_{3}$ for $20 \mathrm{~min}$ at $4{ }^{\circ} \mathrm{C}$. After the gel was rinsed with water, bands development was done in $0.04 \%$ formalin and $2 \% \mathrm{Na}_{2} \mathrm{CO}_{3}$. The development was stopped with $5 \%$ acetic acid and bands were cut out and store in ultrapure water until analysis [56]. 
The protein bands were excised, cut into cubes $\left(1 \mathrm{~mm}^{2}\right)$, deposited in 96-well plates and processed automatically in a Proteineer DP (Bruker Daltonics, Bremen, Germany). The digestion protocol used was based on Schevchenko et al. [56] with minor variations: gel plugs were washed firstly with $50 \mathrm{mM}$ ammonium bicarbonate and secondly with ACN (acetonitrile) prior to reduction with $10 \mathrm{mM}$ DTT (dithiothreitol) in $25 \mathrm{mM}$ ammonium bicarbonate solution, and alkylation was carried out with $55 \mathrm{mM}$ IAA in $50 \mathrm{mM}$ ammonium bicarbonate solution. Gel pieces were then rinsed firstly with $50 \mathrm{mM}$ ammonium bicarbonate and secondly with $\mathrm{ACN}$, and then were dried under a stream of nitrogen. Proteomics Grade Trypsin (Sigma-Aldrich Co., St. Louis, MO, USA) at a final concentration of $16 \mathrm{ng} / \mu \mathrm{L}$ in $25 \% \mathrm{ACN} / 50 \mathrm{mM}$ ammonium bicarbonate solution was added and the digestion took place at $37^{\circ} \mathrm{C}$ for $4 \mathrm{~h}$. The reaction was stopped by adding 50\%ACN/0.5\%TFA for peptide extraction. The tryptic eluted peptides were dried by speed-vacuum centrifugation [65].

Half of each digested sample was subjected to 1D-nano LC ESI-MS/MS analysis using a nano liquid chromatography system (Eksigent Technologies nanoLC Ultra 1D plus, SCIEX, Foster City, CA) coupled to high speed Triple TOF 5600 mass spectrometer (SCIEX, Foster City, CA) with a Nanospray III source. The analytical column used was a silica-based reversed phase Acquity UPLC M-Class Peptide BEH C18 Column, $75 \mu \mathrm{m} \times 150 \mathrm{~mm}, 1.7 \mu \mathrm{m}$ particle sizes and $130 \AA$ pore size (waters). The trap column was a C18 Acclaim PepMapTM 100 (Thermo Scientific), $100 \mu \mathrm{m} \times 2 \mathrm{~cm}, 5 \mu \mathrm{m}$ particle diameter, $100 \AA$ A pore size, switched on-line with the analytical column. The loading pump delivered a solution of $0.1 \%$ formic acid in water at $2 \mu \mathrm{L} / \mathrm{min}$. The nano-pump provided a flow rate of $250 \mathrm{nl} / \mathrm{min}$ and was operated under gradient elution conditions. Peptides were separated using a 40 min gradient ranging from $2 \%$ to $90 \%$ mobile phase B (mobile phase A: $2 \%$ acetonitrile, $0.1 \%$ formic acid; mobile phase B: $100 \%$ acetonitrile, $0.1 \%$ formic acid). Injection volume was $5 \mu \mathrm{L}$ [65].

Data acquisition was performed with a TripleTOF 5600 System (SCIEX, Foster City, CA). Data was acquired using an ionspray voltage floating (ISVF) $2300 \mathrm{~V}$, curtain gas (CUR) 35, interface heater temperature (IHT) 150, ion source gas 1 (GS1) 25 and declustering potential (DP) 100 V. All data was acquired using information-dependent acquisition (IDA) mode with Analyst TF 1.7 software (SCIEX, USA). For IDA parameters, 0.25 s MS survey scan in the mass range of 350-1250 Da were followed by $35 \mathrm{MS} / \mathrm{MS}$ scans of $100 \mathrm{~ms}$ in the mass range of 100-1800 (total cycle time: $4 \mathrm{~s}$ ). Switching criteria were set to ions greater than mass to charge ratio $(\mathrm{m} / \mathrm{z}) 350$ and smaller than $\mathrm{m} / \mathrm{z} 1250$ with a charge state of two to five and an abundance threshold of more than 90 counts (cps). Former target ions were excluded for $15 \mathrm{~s}$. IDA rolling collision energy (CE) parameters script was used for automatically controlling the CE.

Mass spectrometry data obtained were processed using PeakView v2.2 Software (SCIEX) and exported as mgf files which were searched using Mascot Server v2.7.0.1 (Matrix Science, London, UK) against Methylobacterium sp. protein database from Uniprot (last update: 20200608, 257.559 sequences), together with commonly occurring contaminants. Search parameters were set as follows: enzyme, trypsin; allowed missed cleavages, 2; carbamidomethyl (C) as fixed modification and acetyl (Protein N-term), pyrrolidone from E, pyrrolidone from $Q$ and Oxidation (M) as variable modifications. Peptide mass tolerance was set to \pm 25 ppm for precursors and $0.05 \mathrm{Da}$ for fragments masses. The confidence interval for protein identification was set to $\geq 95 \%(p<0.05)$ and only peptides with an individual ion score above 30 were considered correctly identified [65]. All reagents used were acquired in Sigma-Aldrich (Sigma-Aldrich Co., St. Louis, MO, USA).

\section{Conclusions}

In conclusion, exposing a surface to the Methylobacterium sp. extract inhibits $M$. chimaera ECMO biofilm development. Furthermore, this effect could be result of the effect of certain proteins, such as $\mathrm{DNaK}$, trigger factor, and xanthine oxidase. This extract could be used as a pre-treatment prior to disinfection protocols for equipment contaminated with mycobacteria.

Author Contributions: Conceptualization, J.J.A.-C. and J.E.; methodology, J.J.A.-C.; software, J.J.A.-C. and I.P.; validation, J.J.A.-C.; I.P. and J.E.; formal analysis, J.J.A.-C. and I.P.; investigation, J.J.A.-C., I.P., A.M., M.G.-C. and 
J.E.; resources, J.E.; data curation, J.J.A.-C. and I.P.; writing-original draft preparation, J.J.A.-C., I.P. and A.M.; writing-review and editing, J.J.A.-C., I.P., A.M., M.G.-C. and J.E.; visualization, J.J.A.-C. and I.P.; supervision, J.E.; project administration, J.J.A.-C. and J.E.; funding acquisition, J.E. All authors have read and agreed to the published version of the manuscript.

Funding: Instituto de Salud Carlos III: PI18/01068; Instituto de Salud Carlos III: PT17/0019.

Acknowledgments: We wish to acknowledge Oliver Shaw for his help in reviewing the manuscripts for language-related aspects and María del Mar González García-Parreño for her help with the use of the confocal laser-scanning microscope. This study has been funded by Instituto de Salud Carlos III through the project PI18/01068 (co-funded by European Regional Development Fund. ERDF, a way to build Europe). The proteomic analyses were performed in the Proteomics Facility of The Spanish National Center for Biotechnology (CNB-CSIC), which belongs to ProteoRed, PRB3-ISCIII, supported by grant PT17/0019.

Conflicts of Interest: JE received travel grants from Pfizer and conference fees from Biomérieux and Heraeus.

\section{References}

1. Diggle, S.P. Microbial communication and virulence: Lessons from evolutionary theory. Micobriology 2010, 156, 3503-3512. [CrossRef] [PubMed]

2. Alcaide Fernández de Vega, F.; Moreno, J.E.; Martín, J.G.; Gutiérrez, J.J.P. Procedimientos en Microbiología Clínica. 2005. ISBN 8460970329. Available online: https://www.seimc.org/contenidos/documentoscientificos/ procedimientosmicrobiologia/seimc-procedimientomicrobiologia9a.pdf (accessed on 31 December 2005).

3. Mason, R.J.; Slutsky, A.S.; Murray, E.J.; Nadel, J.A.; Gotway, M.B. Nontubercolous mycobacterial infections. In Murray and Nadel's Textbook of Respiratory Medicine; Elsevier: Amsterdam, The Netherlands, 2016.

4. Faria, S.; Joao, I.; Jordao, L. General overview on nontuberculous mycobacteria, biofilms, and human infection. J. Pathog. 2015, 2015, 2-10. [CrossRef] [PubMed]

5. Johnson, M.M.; Odell, J.A. Nontuberculous mycobacterial pulmonary infections. J. Thorac. Dis. 2014, 6, 210-220. [CrossRef] [PubMed]

6. Jarashow, M.C.; Terashita, D.; Balter, S.; Schwartz, B. Mycobacteria Chimaera Infections Associated with Heater-Cooler Unit Use during Cardiopulmonary Bypass Surgery-Los Angeles County, 2012-2016. Am. J. Transplant. 2019, 19, 601-602. [CrossRef]

7. Acosta, F.; Pérez-lago, L.; Jesús, M.; Serrano, R.; Marín, M.; Kohl, T.A.; Lozano, N.; Niemann, S.; Valerio, M.; Olmedo, M.; et al. Fast update of undetected Mycobacterium chimaera infections to reveal unsuspected cases. J. Hosp. Infect. 2018, 152. [CrossRef]

8. Casini, B.; Tuvo, B.; Totaro, M.; Baggiani, A.; Privitera, G. Detection and decontamination of Mycobacterium chimaera and other non-tuberculosis mycobacteria in heater-cooler devices used in cardiopulmonary bypass: A Manufacturer and National guidelines summary, and a potential resolution to the problem requirin. Perfusion 2020, 35, 190-196. [CrossRef]

9. Stefan, P.; Erik, C.; Sax, H.; Bloemberg, G.; Hasse, B.; Sommerstein, R.; Kohler, P.; Achermann, Y. Prolonged outbreak of Mycobacterium chimaera infection after open-chest heart surgery. Clin. Infect. Dis. 2015, 61, 67-75. [CrossRef]

10. European Centre for Disease Prevention and Control. Invasive Cardiovascular Infection by Mycobacterium Chimaera Associated with the 3T Heater-Cooler System Used during Open-Heart Surgery; European Centre for Disease Prevention and Control: Stockholm, Sweden, 2016.

11. Schreiber, P.W.; Sax, H. Mycobacterium chimaera infections associated with heater-cooler units in cardiac surgery. Curr. Opin. 2017, 30. [CrossRef]

12. Haller, S.; Höller, C.; Jacobshagen, A.; Hamouda, O.; Abu Sin, M.; Monnet, D.L.; Plachouras, D.; Eckmanns, T. Contamination during production of heater-cooler units by Mycobacterium chimaera potential cause for invasive cardiovascular infections: Results of an outbreak investigation in Germany, April 2015 to February 2016. Eurosurveillance 2016, 21. [CrossRef]

13. Walker, J.; Moore, G.; Collins, S.; Parks, S.; Garvey, M.I.; Lamagni, T.; Smith, G.; Dawkin, L.; Goldenberg, S.; Chand, M. Microbiological problems and biofilms associated with Mycobacterium chimaera in heater e cooler units used for cardiopulmonary bypass. J. Hosp. Infect. 2017, 96, 209-220. [CrossRef]

14. Chand, M.; Lamagni, T.; Kranzer, K.; Hedge, J.; Moore, G.; Parks, S.; Collins, S.; Elias, O.; Ahmed, N.; Brown, T.; et al. Insidious risk of severe Mycobacterium chimaera infection in cardiac surgery patients. Clin. Infect. Dis. 2017, 64, 335-342. [CrossRef] [PubMed] 
15. Cai, Y.; Landolfo, K.; Renew, J.R. Mycobacterium infection from a cardiopulmonary bypass heater- cooler unit in a patient with steroid-induced immunosuppression. Can. J. Anesth. 2017, 64, 513-516. [CrossRef] [PubMed]

16. Dominguez, F.; Forteza, A.; Garcia-pavia, P.; Ramos-martinez, A. Successful treatment of healthcare-associated Mycobacterium chimaera prosthetic infective endocarditis: The first Spanish case report. Eur. Heart J. 2018, 2, 1-6. [CrossRef]

17. Tan, N.; Sampath, R.; Saleh, O.M.A.; Tweet, M.S. Disseminated Mycobacterium chimaera infection after cardiothoracic surgery. Open Forum Infect. Dis. 2016, 3, 1-3. [CrossRef] [PubMed]

18. Zhang, X.; Lin, J.; Feng, Y.; Wang, X.; Mcnally, A. Identification of Mycobacterium chimaera in heater-cooler units in China. Sci. Rep. 2018, 8, 1-5. [CrossRef]

19. Scriven, J.E.; Scobie, A.; Verlander, N.Q.; Houston, A.; Collyns, T.; Cajic, V.; Kon, O.M.; Mitchell, T.; Rahama, O.; Robinson, A.; et al. Mycobacterium chimaera infection following cardiac surgery in the United Kingdom: Clinical features and outcome of the first 30 cases. Clin. Microbiol. Infect. 2018, 24, 1164-1170. [CrossRef]

20. Sommerstein, R.; Hasse, B.; Marschall, J.; Sax, H.; Genoni, M.; Schlegel, M.; Widmer, A.F. Global health estimate of invasive mycobacterium chimaera infections associated with heater-cooler devices in cardiac surgery. Emerg. Infect. Dis. 2018, 24, 1-3. [CrossRef]

21. Sommerstein, R.; Rüegg, C.; Kohler, P.; Bloemberg, G.; Kuster, S.P.; Sax, H. Transmission of Mycobacterium chimaera from heater-cooler units during crdiac surgery despite an ultraclean air ventilation system. Emerg. Infect. Dis. 2016, 22, 2-7. [CrossRef]

22. Nihn, A.; Weiner, M.; Goldberg, A. Healthcare-associated Mycobacterium chimaera infection subsequent to heater-cooler device exposure during cardiac surgery. J. Cardiothorac. Vasc. Anesth. 2017, 31, 1831-1835. [CrossRef]

23. Kohler, P.; Kuster, S.P.; Bloemberg, G.; Schulthess, B.; Bo, C.; Falk, V.; Frank, M.; Tanner, F.C.; Ro, M.; Wilhelm, M.J.; et al. Healthcare-associated prosthetic heart valve, aortic vascular graft, and disseminated Mycobacterium chimaera infections subsequent to open heart surgery. Eur. Heart J. 2015, 36, 2745-2753. [CrossRef]

24. Ryu, Y.J.; Koh, W.; Daley, C.L. Diagnosis and treatment of nontuberculous mycobacterial lung disease: clinicians' perspectives. Tuberc. Respir. Dis. (Seoul) 2016, 79, 74-84. [CrossRef] [PubMed]

25. Schreiber, P.W.; Kuster, S.P.; Hasse, B.; Bayard, C.; Rüegg, C.; Kohler, P.; Keller, P.M.; Bloemberg, G.V.; Maisano, F.; Bettex, D.; et al. Reemergence of Mycobacterium chimaera in heater-cooler units despite intesified clining and disinfection protocol. Emerg. Infect. Dis. 2016, 22, 2-5. [CrossRef] [PubMed]

26. Stewardson, A.J.; Stuart, R.L.; Cheng, A.C. Mycobacterium chimaera and cardiac surgery. Med. J. Aust. 2016, 206, 132-135. [CrossRef] [PubMed]

27. Garvey, M.I.; Phillips, N.; Bradley, C.W.; Holden, E. Decontamination of an extracorporeal membrane oxygenator contaminated with mycobacterium chimaera. Infect. Control. Hosp. Epidemiol. 2017, 38, 1244-1246. [CrossRef]

28. Martí, M.C.; Bermejo, B.B.; Gil, L.A. Infections with Mycobacterium chimaera and open chest surgery. An unresolved problem. Med. Clin. (Barc). 2019, 152, 317-323. [CrossRef]

29. Sommerstein, R.; Schreiber, P.W.; Diekema, D.J.; Edmond, M.B.; Hasse, B.; Marschall, J.; Sax,H. Mycobacterium chimaera outbreak associated with Heater-Cooler Devices: Piecing the puzzle together. Infect. Control. Hosp. Epidemiol. 2017, 38. [CrossRef]

30. Kaelin, M.B.; Kuster, S.P.; Hasse, B.; Schulthess, B.; Imkamp, F.; Halbe, M.; Sander, P.; Sax, H.; Schreiber, P.W. Diversity of nontuberculous mycobacteria in Heater-Cooler Devices-results from prospective surveillance. J. Hosp. Infect. 2020. [CrossRef]

31. Perkins, K.M.; Lawsin, A.; Hasan, N.A.; Strong, M.; Halpin, A.L.; Rodger, R.R.; Moulton-Meissner, H.; Crist, M.B.; Schwartz, S.; Marders, J.; et al. Mycobacterium Chimaera Contamination of Heater-Cooler Devices Used in Cardiac Surgery-United States. In MMWR. Morbidity and Mortality Weekly Report 2016; Centers for Disease Control and Prevention: Atlanta, GA, USA, 2016; Volume 65.

32. Esteban, J.; García-coca, M. Mycobacterium biofilms. Front. Microbiol. 2018, 8, 1-8. [CrossRef]

33. García-Coca, M.; Rodríguez-Sevilla, G.; Aguilera-Correa, J.-J.; Esteban-Moreno, J.; Muño-Egea, M.-C. Inhibition of Mycobacterium chelonae and Mycobacterium fortuitum biofilms by Methylobacterium sp. In Proceedings of the European Congress of Clinical Micobiology and Infectious Diseases, Madrid, Spain, 21-24 April 2018. 
34. Patt, T.E.; Cole, G.C.; Hanson, R.S. Methylobacterium, a new genus of facultatively methylotrophic bacteria. Int. J. Syst. Bacteriol. 1976, 26, 226-229. [CrossRef]

35. Egea, M.C.M.; Ji, P.; Pruden, A.; Falkinham, J.O. Inhibition of adherence of mycobacterium avium to plumbing surface biofilms of Methylobacterium spp. Pathogens 2017, 6, 42. [CrossRef]

36. Balachandran, C.; Duraipandiyan, V.; Ignacimuthu, S. Cytotoxic (A549) and antimicrobial effects of Methylobacterium sp. isolate (ERI-135) from Nilgiris forest soil, India. Asian Pac. J. Trop. Biomed. 2012, 2, 712-716. [CrossRef]

37. Tejesvi, M.V.; Andersen, B. MB1533 is a defensin-like antimicrobial peptide from the intracellular meristem endophyte of Scots Pine Methylobacterium extorquens DSM13060. J. Microb. Biochem. Technol. 2015, 08, 1-5. [CrossRef]

38. Photolo, M.M.; Mavumengwana, V.; Sitole, L.; Tlou, M.G. Antimicrobial and Antioxidant Properties of a Bacterial Endophyte, Methylobacterium radiotolerans MAMP 4754, Isolated from Combretum erythrophyllum seeds. Int. J. Microbiol. 2020, 2020. [CrossRef] [PubMed]

39. Muñoz-Egea, M.-C.; García-Pedrazuela, M.; Mahillo, I.; García, M.J.; Esteban, J. Autofluorescence as a tool for structural analysis of biofilms formed by nonpigmented rapidly growing Mycobacteria. Appl. Environ. Microbiol. 2013, 79, 1065-1067. [CrossRef]

40. Wang, C.; Zhang, Q.; Tang, X.; An, Y.; Li, S.; Xu, H.; Li, Y.; Wang, X.; Luan, W.; Wang, Y.; et al. Effects of CwlM on autolysis and biofilm formation in Mycobacterium tuberculosis and Mycobacterium smegmatis. Int. J. Med. Microbiol. 2019, 309, 73-83. [CrossRef] [PubMed]

41. Sharma, I.M.; Petchiappan, A.; Chatterji, D. Quorum sensing and biofilm formation in Mycobacteria: Role of c-di-GMP and methods to study this second messenger. Int. Union Biochem. Mol. Biol. 2014, 66, 823-834. [CrossRef] [PubMed]

42. Singh, V.K.; Mishra, A.; Jha, B. Anti-quorum sensing and anti-biofilm activity of Delftia tsuruhatensis extract by attenuating the quorum sensing-controlled virulence factor production in Pseudomonas aeruginosa. Front. Cell. Infect. Microbiol. 2017, 7, 1-16. [CrossRef]

43. Chow, J.Y.; Wu, L.; Yew, W.S. Directed evolution of a quorum-quenching lactonase from Mycobacterium avium subsp. paratuberculosis K-10 in the amidohydrolase superfamily. Biochemistry 2009, 48, 4344-4353. [CrossRef]

44. Milon, P.; Carotti, M.; Konevega, A.L.; Wintermeyer, W.; Rodnina, M.V.; Gualerzi, C.O. The ribosome-bound initiation factor 2 recruits initiator tRNA to the 30 S initiation complex. EMBO Rep. 2010, 11, 312-316. [CrossRef]

45. Delvillani, F.; Papiani, G.; Dehó, G.; Briani, F. S1 ribosomal protein and the interplay between translation and mRNA decay. Nucleic Acids Res. 2011, 39, 7702-7715. [CrossRef]

46. Savelsbergh, A.; Rodnina, M.V.; Wintermeyer, W. Distinct functions of elongation factor G in ribosome recycling and translocation. RNA 2009, 15, 772-780. [CrossRef] [PubMed]

47. Aguilar-Rodríguez, J.; Sabater-Muñoz, B.; Montagud-Martínez, R.; Berlanga, V.; Alvarez-Ponce, D.; Wagner, A.; Fares, M.A. The molecular chaperone dnak is a source of mutational robustness. Genome Biol. Evol. 2016, 8, 2979-2991. [CrossRef] [PubMed]

48. Falkinham, J.O. Challenges of NTM drug development. Front. Microbiol. 2018, 9, 1-7. [CrossRef] [PubMed]

49. Chistoserdova, L.; Crowther, G.J.; Vorholt, J.A.; Skovran, E.; Portais, J.C.; Lidstrom, M.E. Identification of a fourth formate dehydrogenase in Methylobacterium extorquens AM1 and confirmation of the essential role of formate oxidation in methylotrophy. J. Bacteriol. 2007, 189, 9076-9081. [CrossRef] [PubMed]

50. Tsujii, A.; Nishino, T. Mechanism of transition from xanthine dehydrogenase to xanthine oxidase: Effect of guanidine-HCL or urea on the activity. Nucleosides Nucleotides Nucleic Acids 2008, 27, 881-887. [CrossRef]

51. Bonini, M.G.; Miyamoto, S.; Di Mascio, P.; Augusto, O. Production of the carbonate radical anion during xanthine oxidase turnover in the presence of bicarbonate. J. Biol. Chem. 2004, 279, 51836-51843. [CrossRef]

52. Blombach, B.; Takors, R. CO2-Intrinsic product, essential substrate, and regulatory trigger of microbial and mammalian production processes. Front. Bioeng. Biotechnol. 2015, 3, 1-11. [CrossRef]

53. Tomioka, H.; Sato, K.; Sano, C.; Akaki, T.; Shimizu, T.; Kajitani, H.; Saito, H. Effector molecules of the host defence mechanism against Mycobacterium avium complex: The evidence showing that reactive oxygen intermediates, reactive nitrogen intermediates, and free fatty acids each alone are not decisive in expression of macrophage an. Clin. Exp. Immunol. 1997, 109, 248-254. [CrossRef] 
54. Danielyan, K.E.; Simonyan, A.A. Protective abilities of pyridoxine in experimental oxidative stress settings in vivo and in vitro. Biomed. Pharmacother. 2017, 86, 537-540. [CrossRef]

55. Dick, T.; Manjunatha, U.; Kappes, B.; Gengenbacher, M. Vitamin B6 biosynthesis is essential for survival and virulence of Mycobacterium tuberculosis. Mol. Microbiol. 2010, 78, 980-988. [CrossRef]

56. Falkinham, J.O. Disinfection and cleaning of heater-cooler units: Suspension- and biofilm-killing. J. Hosp. Infect. 2020. [CrossRef]

57. Witko, A. Effect of natural and physical agents. Effect of desiccation. In Inhibition and Destruction of the Microbial Cell; Academic Press: Cambridge, MA, USA, 2003; p. 425, ISBN 3904144987.

58. Pitcher, R.S.; Green, A.J.; Brzostek, A.; Korycka-Machala, M.; Dziadek, J.; Doherty, A.J. NHEJ protects mycobacteria in stationary phase against the harmful effects of desiccation. DNA Repair (Amst). 2007, 6, 1271-1276. [CrossRef] [PubMed]

59. Chakraborty, P.; Kumar, A. The extracellular matrix of mycobacterial biofilms: Could we shorten the treatment of mycobacterial infections? Microb. Cell 2019, 6, 105-122. [CrossRef] [PubMed]

60. Mai-Prochnow, A.; Webb, J.S.; Ferrari, B.C.; Kjelleberg, S. Ecological advantages of autolysis during the development and dispersal of Pseudoalteromonas tunicata biofilms. Appl. Environ. Microbiol. 2006, 72, 5414-5420. [CrossRef] [PubMed]

61. García-Coca, M.; Perez-Domingo, A.; Esteban-Moreno, J.; Muñoz-Egea, M.-C. Effect of Methylobacterium sp. combined with clarithromycin on Mycobacterium abscessus biofilms. In Proceedings of the European Congress of Clinical Micobiology and Infectious Diseases, Madrid, Spain, 21-24 April 2018.

62. García-Coca, M.; Rodríguez-Sevilla, G.; Pérez-Domingo, A.; Aguilera-Correa, J.-J.; Esteban, J.; Muñoz-Egea, M.-C. Inhibition of Mycobacterium abscessus, M. chelonae, and M. fortuitum biofilms by Methylobacterium sp. J. Antibiot. (Tokyo) 2019. [CrossRef]

63. Herigstad, B.; Hamilton, M.; Heersink, J. How to optimize the drop plate method for enumerating bacteria. J. Microbiol. Methods 2001, 44, 121-129. [CrossRef]

64. Conesa-Buendía, F.M.; Llamas-Granda, P.; Larrañaga-Vera, A.; Wilder, T.; Largo, R.; Herrero-Beaumont, G.; Cronstein, B.; Mediero, A. Tenofovir causes bone loss via decreased bone formation and increased bone resorption, which can be counteracted by dipyridamole in mice. J. Bone Miner. Res. 2019, 34, 923-938. [CrossRef]

65. Shevchenko, A.; Wilm, M.; Vorm, O.; Mann, M. Mass spectrometric sequencing of proteins from silver-stained polyacrylamide gels. Anal. Chem. 1996, 68, 850-858. [CrossRef] 